\title{
A DMS-based Design for the Informatization of Tourism in Leshan
}

\author{
Zhen Li \\ The Engineering \& Technical College of Chengdu University of Technology, Leshan, 614000, P.R. \\ China
}

373622122@qq.com

Keywords: Destination marketing system; Tourism; Informatization

\begin{abstract}
In recent years, tourism has been playing a more and more important role in Leshan's economy as it continues to thrive. Therefore, how to informatize tourism is a challenge but also an opportunity for Leshan to develop its local tourism. This paper is to propose a DMS-based design for the informatization of tourism in Leshan, with the analysis on DMS and the realities of tourism in Leshan.
\end{abstract}

\section{Introduction}

DMS (Destination Marketing System) is a complete solving method for a tourist destination to market its tourism products on the Internet to. The targets of DMS are to improve the marketing level of a destination, to standardize the informatization process, to help the local tourist office manage tourism enterprises, to enhance the status of a destination, and to increase the flow of people in a destination to consume to make profits.

\section{The Realities of Tourism Informatization in Leshan}

The Current Situation. Information network infrastructure for tourism in Leshan is developing very fast and so is e-government construction. For Leshan Giant Buddha, and Mount Emei, the two world's natural and cultural heritage sites, the government has set up and been operating "Digital Leshan Giant Buddha" and "Digital Mount Emei".

Problems. Although the tourism informatization in Leshan has achieved a certain achievements, there are still a great gap, compared with the requirements of the informatization of cultural heritage sites and the development of the informatization in other fields in China. The gap is mainly represented in the following aspects

(1) The local government and enterprises do not well perceive the importance and significance of tourism informatization, or know little about the basic rules of informatization. In some places of Leshan, the local governments and departments do not set up a unified and effective system for management and operation of informatization, and they have little awareness of how to develop the natural and cultural heritages and how to manage and market their tourism products.

(2) as the local government do not perceive the importance of overall planning and standardization of rules and regulations, the study on making and standardizing rules and regulations lags behind, which leads to lack of coordination, low-level duplicated construction, poor universal application and so on, and hinders the sharing of information of natural and cultural heritages and the coordination of tourism informatization in China.

(3) Information infrastructure lags behind. Compared with the developments in other industries and fields, the information infrastructure for tourism in Leshan is in a lower level. Only in certain places and offices in charge of natural and cultural heritage sites the networks and databases have been set up, which for sure cannot store and exchange information in large amount for the development of natural and cultural heritage sites. Meanwhile, the present networks and databases are short of measures for system security and need the data backup system and certificate authority system to be perfected. 
(4) Serious shortage of fund is a key factor to hinder the development of tourism informatization. That is why the tourism informatization in Leshan goes slowly and it is difficult for tourism networks and systems to collect, and process information.

(5) Experts in information technology are still in badly need. There is no complete system for information training for the staff in tourist offices. Because of this, the staff's ability of applying information technology is below. Meanwhile, the staff in the informatization of natural and cultural heritage sites are serious short and their knowledge in this field is not enough and needs to be broadened. Therefore, Leshan starve for the people who are good at information technology and have professional knowledge of natural and cultural heritage.

\section{A DMS-based Design for Tourism Informatization in Leshan}

Tourism informatization in Leshan mainly focuses on the establishment and operation of DMS, the establishment and operation of supporting facilities related to tourism consultancy, and a complete service network for a destination to share information and make profits. In the following part, factors to affect DMS and the DMS-based design will be discussed in detail.

Factors to DMS. DMS has been regarded as a relative advance means to market a tourist destination on the Internet and been applied in many places. But up to now, most DMSs supported by the government at home and abroad have only developed their informative function, and not supported their functions of online trading, or there has been no healthy model of operation without the support of enterprises or the government at the beginning of the establishment of these DMSs, which makes their online trading cannot meet the customers' demand. The factors to affect a DMS to work well include

(1) Strategic foresight of the team in charge of DMS,

(2) Executive ability of and capital investment to the team,

(3) Effective communication,

(4) highlighted tourism brand and image of a destination,

(5) Information technology to be oriented,

(6) Tourism products as the directed behavior,

(7) Services for tourists' demands provided with all things considered,

(8) Rational application of network techniques.

Therefore, if we want to establish a healthy DMS, first we should have a tourism system with rich information and complete functions for the public to get the information they want. Then, the functions of a DMS should take all the interests of participants into consideration. The DMS of tourist destinations abroad are different in system development and operation. Some is invested by the government, while some by the government and business organizations. And each tourist destination has the right to make the final decisions to buy a DMS or develop a DMS by itself.

The DMS-based Design. The DMS, which the government encourages and markets to tourist destinations in China, is developed by Yahtour Company which is cooperating with China National Tourism Administration. Although the tourist destinations are not forced to apply the DMS, it, to a great extent, sets a bar for other network service provider to enter the field, which is harmful for information technology to be applied in tourism market. Besides, a tourist destination should conform to rules and regulations and follow the steps of developing, no matter whether it applies the DMS the government recommends or develop a DMS by itself, or redevelop the DMS the government recommends with its own features. The DMS-based design proposed in the following is consistent with the steps for development made by World Tourism Organization in 2001 and the features and realities of tourism in Leshan. Here are the detailed descriptions

(1) The DMS should have its distinguished functions and features. First, the image of the tourist destination should be firmly established and all the designs of the website should center on the image to impress the customers. Second, the functions of the DMS should be clearly defined, such as its informative function, marketing function and trading function. Third, the target the DMS services should be identified so that the DMS can effectively provide information for different customers. Last, 
the websites for public service of the DMS should be designed and established according to their functions and features.

(2) The government should work with other interest parties to determine the operation mode. First, figure out the sources of fund and investment, invested and owned by the government, or by the government and enterprises, or only by the enterprises. Then, do a research on market and consult all levels of tourism to make sure that the DMS will be supported by the local government and other interest parties. Besides, try to get enterprises, associations and other interest parties to participate in the development of the DMS and learn about the operation modes of partners, which is very important to the practicality of the websites and the services the website provides. And then, find a right way to cooperate with partners so as to invite more people to take part in. Furthermore, make sure of the financial situation of the DMS. Then, find out the online channels to sell tourism products by own websites or by the cooperation with other places. The portals, travel websites and so on could reach an agreement to expand the channels for marketing and also should know clearly about their profits. Then, estimate the trade value to know the cost and profit of each deal and build a financial model to analyze the commission rate, financial structure and early investment to make sure the website can function well and partners can make profits. Meanwhile, figure out the way to publicize and update information, and the cost and partners for publicizing and updating information. Last, analyze the cost and profit in a long term, considering the technology as the hardware and software should be updated every two or three years.

(3) The related software and hardware should be well-prepared. A tourist destination should well know the present destination marketing systems and then decide which to be applied, to use the DMS recommended by China National Tourism Administration, or to develop by itself, or redevelop $\mathrm{s}$ existing DMS. It should decide whether it buys a server or rents a server from internet providers. It works with the technology developers, providers in charge of content, interest bodies and customers to decide the hardware and software of the DMS. It must standardize its rules and regulations according to the national standards in the tourism data transmission. The development of the DMS should consider whether the tourism information can be publicized in multimedia creatively, whether the way to publicize information is suitable for the customer's net environment so that the customers can browse and download, whether the information is related and logically arranged, whether the sub-websites are needed for the enterprises or special customers and whether other language versions of websites besides Chinese are needed. The DMS should be established step by step and for each step, and should be testified and verified according to the feedbacks from enterprises, customers, and administrative workers

(4) The design and establishment of websites should be confirmed and operated. First, a domain name of a tourist destination should be simple, highlighted, and easy to be remembered so that the name could be in the front on the list by search engines. The design of the website should be attractive, concise and logical with a distinguished theme for people to browse and download information. The contents of the website should be properly classified and publicized through various channels with the site map, navigation and help for customers to look for the information. The website should provide channels for consultancy and booking to help customers and website interact and listen to the feedbacks of customers to the system.

(5) Information about a tourist destination and products should be collected, processed and compressed in multimedia materials. A tourist destination should collect and process the publications, pictures, maps and videos and other materials in tourism and gradually electronize these materials, which it should make sure that there are enough money and workers to collect and update information. All electronic materials should be classified, selected and stored for search and use. The contents of the website should fit in with the image and brand of the tourist destination.

(6) The DMS should be testified. After the development, the DMS should be testified to be verified to make sure all the date is accurate and timely. Therefore, in the trial process, the developer should listen to the feedbacks and suggestions to find out the problems, and constantly check the stability of the website, the speed for downloading, and the place of the domain name of the tourist destination in 
the list of search engines, the website visits and booking.

(7) Website promotion is very important. When a website is put in the trial, it should be registered and optimalized by the major search engines to make sure of its position. Then try to enhance its fame online and offline. For example, we can perfect the website, link with other famous websites, update the information and so on; and put advertisements on publications or traditional media, or do some promotional activities to market the tourist destination.

The Establishment and Operation of Supporting Facilities. (1) Tourism Information

The application of information technology and the establishment of information system is not the only criterion to judge the service of a tourist destination. The facilities to provide information, the free information materials about the tourist destination, the service awareness and quality of the working staff and so on are very important and significant to the development of the tourist destination.

Tourism information can be provided through two ways: online service and offline service. Online service refers to the call center, online information inquiry center, and the touch screens on scenic spots. To be specific, hotels and inquiry centers set up an information system for customers to search and based on it they take advantage of the supporting facilities to expand the tourism information by the touch screens or inquiry systems.

Offline service refers to the advertisements and leaflets of the tourist destination. The contents of the two are processed by the databases and distributed in airports, stations, hotels, inquiry stands to customers so that the customers can enjoy their travelling and feel the considerate service.

(2) Measures to Check Supporting Facilities

There are several ways to check whether the supporting facilities are established scientifically and provides timely information such as the speed and accuracy of information to and from the call center, the hospitality of the working staff, the availability of public information tools, the conciseness and attractiveness of the information facilities, the standardization of languages and symbols, the service quality of working staff, and the quality of tourism publications which would ensure that the customers would not throw the publications as rubbish so as to draw more people to the tourist destination.

\section{References}

[1] Pan Le. On the information construction of Leshan cultural heritage tourism resources, Market modernization, vol.538, pp. 304-305, 2008.

[2] CHEN Shuo. Research on the information of tourism destination under the government's leading strategy, East China Normal University, 2006.

[3] Hu Fangping, To create a cultural tourism in Leshan, Jounal of the Party School of Leshan Municipal Committee of C.P.C, vol.8, pp. 50-51, 2007.

[4] Fu Xi san. Discussion on the information of Tourism Management under the guidance of the government. Commercial Times, 2009, 7.

[5] Gao jin. Tourism destination marketing system and its coordination mechanism. Qingdao University. 2005. 